\title{
Prey selection among Los Angeles car thieves
}

\author{
P Jeffrey Brantingham
}

\begin{abstract}
More than 63,000 cars were reported stolen in Los Angeles in 2003-04. However, the distribution of thefts across car types is very uneven. Some cars types such as the Honda Civic were stolen at much higher frequencies than the majority of car types. Charnov's classic prey selection model suggests that such uneven targeting should be related to variations in the environmental abundance, expected payoffs, and handling costs associated with different car types. Street-based surveys in Los Angeles suggest that differences in abundance explain the majority of thefts. Cars stolen despite being rare may reflect offender preference based on differential payoffs, probably in some non-monetary currency such as prestige or excitement. Differential handling costs play a more ambiguous role in target selection, but may underlie thieves' decisions to ignore some cars common in the environment. The unspecialized nature of car theft in Los Angeles suggests that the behavioral and cognitive capacities needed to be a successful car thief are generic. The evolved capacity to solve foraging problems in boundedly-rational ways, mixed with small amounts of trial-and-error and/or social learning, are sufficient to produce experts from inexperienced thieves.

Keywords: Crime; Environmental criminology; Behavioral ecology; Optimal foraging; Bounded-rationality; Social learning
\end{abstract}

\section{Background}

The rational choice theory of crime holds that offenders engage in crime because they stand to receive significant short-term benefits with little attendant risk and small associated costs (Cornish and Clarke 1986, 1987). Presented with a suitable target or victim, unguarded by an effective security measure, the reasoning offender generally capitalizes on that opportunity (Felson and Clarke 1998; Freeman 1996). Beyond implying a common-sense relationship between benefits and costs, however, rational choice theory does not immediately identify what makes any given victim or target suitable. A conceptual framework introduced by Clarke (1999) suggests that property targets are suitable when they are concealable, removable, available, valuable, enjoyable and disposable, capturing several of the dimensions of costs and benefits that are important in offender decision making. While useful, the so-called CRAVED approach also leaves much unspecified about the relative importance of relationships among the different dimensions of target suitability.

Correspondence: branting@ucla.edu

Department of Anthropology, University of California, Los Angeles,

341 Haines Hall, UCLA, Box 951553, Los Angeles, CA 90095-1553, USA
Here I turn to theory arising outside of criminology to provide a formal framework in which understand the relationships between target characteristics and offender target selection. Specifically, I use Charnov's (1976) prey selection model to evaluate offender choice to steal different car types. The prey selection model postulates that a forager will ignore a particular prey type upon encounter if the expected return from a future prey encounter is greater. Preference in Charnov's model is defined in terms of the relative abundance of different prey types and their respective handling costs and payoffs upon consumption. Intuitively, prey that are easy to handle or have high payoffs may be preferred but rarely taken, if they are rarely encountered. Prey that are hard to handle or have low payoffs may still be taken, if more profitable prey are rarely encountered. Here the predictions of Charnov's prey selection model are rejected based on findings that unique car types are stolen almost exclusively in response to their environmental availability. Only occasionally are cars targeted because they have higher perceived payoffs. Overall, Los Angeles car thieves operate primarily as unspecialized foragers.

\section{曾}

(c) 2013 Brantingham; licensee Springer. This is an Open Access article distributed under the terms of the Creative Commons Attribution License (http://creativecommons.org/licenses/by/2.0), which permits unrestricted use, distribution, and reproduction in any medium, provided the original work is properly cited. 


\section{Optimal foraging theory and crime}

Foraging theory is the branch of ecology that seeks to understand how animal behavior facilitates the encounter, acquisition and processing of resources necessary to survival (Stephens and Krebs 1986). The foraging challenges facing an animal are substantial. Essential resources are rarely located in the same location as the animal needing them, necessitating behaviors that either carry the animal to the resources, or position the animal to intercept resources that move. Many resource types possess defenses that aim to thwart acquisition, even after a forager has encountered them. Animals therefore need behavioral strategies designed discriminate among resource types and defeat their defenses once they have decided to acquire them. Finally, even after a resource as been encountered and acquired, it may contain a mixture of useable and unusable constituents. Behaviors may play a key role in sorting and separating these constituents. Only after jumping these foraging hurdles may an animal benefit from the resource. Recognize, however, that the behaviors deployed to facilitate encounter, acquisition and processing of a resources are not cost free. Optimal foraging theory therefore posits that evolution and/or learning has shaped animal behavior to maximize the average or long-term return rate from essential resources, net the costs of encounter, acquisition and processing. Here I cast car theft as a foraging problem and test the proposition that the specific car types stolen represent behaviors consistent with optimal foraging theory.

Three conditions must be met to consider car theft as an optimal foraging problem (see also Bernasco 2009; Felson 2006; Johnson et al. 2009). First, car theft should satisfy a need that is perceived by the offender to be essential. Car thieves report a range of motivations for stealing cars including financial motives such as theftfor-export or an immediate need for cash, mundane or routine motives such as transportation, and recreational motives such as a search for excitement, prestige or status (Copes 2003; Dhami 2008; Kellett and Gross 2006; Lantsman 2013; Light et al. 1993). With the exception of theft-for-transport, car theft is not remarkable in motivation compared with other crimes (Wright et al. 2006; Wright and Decker 1994). However, car theft may be a comparably low risk alternative to satisfy these needs (Copes and Tewksbury 2011). Between 2003 and 2006, $\sim 12.9 \%$ of reported car thefts in the US were cleared by arrests, while robberies over the same period were cleared at a rate twice as high $\sim 25.8 \%$ (Federal Bureau of Investigation 2003-2006). The vast majority of car thefts therefore entail no negative consequences, at least over the short term (Freeman 1999). The benefits may therefore be substantial. Payoffs to car theft might be calculated in a cash currency, if cars and/or their parts are being fenced (Clarke 1999; Tremblay et al. 2001). Payoffs might also be calculated in non-cash commodities such as barter value in drugs (Stevenson and Forsythe 1998) or prestige and excitement-an essential resource for joy riding teenagers (Copes 2003; Jacobs et al. 2003; Kellett and Gross 2006).

Second, car thieves must also have behavioral alternatives to deploy during foraging and these alternatives must result in different payoff outcomes. Ethnographic evidence indicates that car theft involves choices between alternative search strategies, tools and techniques for gaining entry and 'hot wiring' targeted vehicles, and strategies for escape and disposal of stolen vehicles (Copes and Cherbonneau 2006; Copes and Tewksbury 2011; Farrell et al. 2011; Langworthy and Lebeau 1992; Lantsman 2013; Light et al. 1993; Lu 2003). Whether these different behavioral alternatives lead to real differences in payoffs is an open question. The observation that different car types are stolen to satisfy different needs may imply differential payoffs (Clarke 1999). However, the extent to which alternative behavioral strategies drive these payoffs, as required by optimal foraging theory, is unknown.

Finally, there must be a mechanism by which car thieves select among the alternative behaviors, yielding near-optimal strategies for locating, stealing and disposing of cars. Simple trial-and-error and/or social learning in the context of co-offending appear to play this role (Akers 2008; Reiss and Farrington 1991). Juvenile car thieves often start as passengers, observing the actions of their more experienced friends (Light et al. 1993). Such learning mechanisms seem capable quickly producing effective cognitive scripts that car thieves can adhere to during commission of a crime (Tremblay et al. 2001).

\section{The prey selection model}

The foraging problem confronted by car thieves is similar in many ways to prey selection, a classical problem in behavioral ecology studied by Charnov (1976) and others (see Krebs et al. 1977; Stephens and Krebs 1986). Given sequential encounters with prey types, each having different expected returns and handling costs, which types should be pursued and captured? Let $e_{i}, h_{i}$ and $\lambda_{i}$ be the expected payoff, handling cost and local density of a prey of type $i$. Prey types $i=1,2, \ldots N$ are ranked in descending order of the ratio of payoff to handling cost $e_{i} / h_{i}$. The prey classification algorithm says that prey types $i=$ $1,2, \ldots j$ should be pursued and captured upon encounter, but prey type $j+1$ should be ignored if its payoff to handling cost ratio is below the mean for all higher ranked prey: 


$$
\frac{\sum_{i=1}^{j} \lambda_{i} e_{i}}{1+\sum_{i=1}^{j} \lambda_{i} h_{i}}>\frac{e_{j+1}}{h_{j+1}}
$$

In other words, if the expected return from future prey encounters is higher than would be gained by taking the current target, then it is better to wait.

The prey choice model makes two distinctive predictions. First, prey types are either always taken upon encounter, or always ignored. This is the so-called "zero-one" rule in reference to the analytical result that an attack on prey type $i$ will occur with probability $q_{i}=0$, or $q_{i}=1$, and nothing in between (Stephens and Krebs 1986). Second, whether or not a prey type is taken is dependent only on the encounter rate with higherranked prey, not its own encounter rate. Note that the term $\lambda_{i}$ appears only on the left-hand side in Equation (1). The implication is that only changes in the encounter rate with higher ranked prey items will impact the decision to attack a lower ranked prey item once it has been encountered. Thus, if a higher ranked prey type becomes very scarce, a lower ranked prey type may be added to the diet. However, if a lower ranked prey type suddenly becomes very common, it will not necessarily be added to the diet without a concomitant change in the rate of encounter with higher ranked types. Empirical evidence from both animal (Hughes and Dunkin 1984; Prugh 2005; but see Pyke 1984) and human foragers (Hames and Vickers 1982; Smith 1991) suggests that the prey classification algorithm provides insights into prey selection behavior across a diverse range of taxa and foraging contexts.

Car theft may be considered a special case of prey selection if car types vary in expected payoffs, handling costs and/or local abundance and offenders are attentive to these differences. As discussed in the Methods section, the available data on payoffs and handling times do not allow for a fine-grained test of either the zero-one rule, or the hypothesis that changes in the encounter rate with higher-ranked car types impact the inclusion of lower ranked car types in an offender's 'diet'. A strict reading of the prey choice model also suggests that car theft may not perfectly conform to all of its assumptions (see for comparison Smith 1991). The prey choice model assumes that: (1) foragers are long-term rate maximizers, meaning that average results of stealing cars over long time periods, rather than short-term gains, are optimized by different foraging strategies; (2) searching for and handling of targeted vehicles are mutually exclusive; (3) encounters with vehicles follow a Poisson process, meaning that two cars cannot be encountered simultaneously and each encounter is statistically independent of all others; (4) the payoff to stealing cars $e_{i}$, the handling costs $h_{i}$, and encounter rates $\lambda_{i}$ are environmentally fixed in time and space; and (5) that the foraging car thief has perfect information about $e_{i}, h_{i}$ and $\lambda_{i}$.

Assumptions 1, 2, 3 and 5 may be reasonable for car theft. The notion that criminal behavioral strategies might be shaped by learning to produce long-term average rate maximization (Assumption 1) seems far fetched at first (but see Tremblay and Morselli 2000). Criminal offenders tend to be present-oriented (Gottfredson and Hirschi 1990; Nagin and Paternoster 1994) and therefore appear little concerned with the long-term costs and benefits of crime (Wilson and Abrahamse 1992). However, the question at hand is not whether crime pays relative to non-crime alternatives, but rather whether stealing one car type is more profitable in the long run than stealing an alternative car type. It is conceivable that offenders adopt strategies that maximize the longterm or average payoffs from car theft by making discriminating choices about which cars to steal.

It is also reasonable to suppose that simultaneous search for cars to steal and the physical act stealing a car are mutually exclusive activities (Assumption 2). This is made more complicated by co-offending, which is quite common for younger car thieves (Light et al. 1993), if some in an offending party search nearby targets while others are breaking into a given car.

It is unknown whether encounters with cars to steal follow a Poisson process (Assumption 3). Ultimately, this is an empirical question for which data need to be collected. Conceptually, however, a motivated car thief walking down a linear street segment encounters cars sequentially and independently. Whether such conditions hold in a parking lot may depend on situational factors such as the layout of and available observation points in the lot. The prey choice model is not obviated under these circumstances (Stephens and Krebs 1986: 38-45), but additional costs associated with discriminating between simultaneously encountered car types must be taken into account.

Perhaps the greatest challenge comes from strictly assuming that the key parameters of prey selection remain fixed in time and space (Assumption 4) (Suresh and Tewksbury 2013). At intermediate time scales (months to years), the payoffs to stealing different car types certainly change with turnover in the composition of cars on the street. Early and late model years may differ significantly in both perceived or actual value as well as handling costs, for example, following the introduction of RFID keys for ignition systems (Farrell et al. 2011). Similarly, there may be short-term (hourly-daily) fluctuations in environmental abundance of cars parked in locations where they might be stolen. Nevertheless, it is reasonable to assume that car thieves have relatively 
accurate knowledge of the encounter rates, payoffs and handling costs associated with different cars, or learn them very quickly when conditions change (Assumption 5) (Akers 2008; Light et al. 1993).

Given the above limitations, I test a conservative null hypothesis in place of the two detailed predictions made by the prey selection model:

- H0. If every car yields the same payoff and all are equally difficult to steal (i. e., $e_{i} / h_{i}=e_{j} / h_{j} \forall i, j$ ), then differences in theft rates arise only from differences in relative abundances of car types $\lambda_{i}$.

In other words, if all cars rank equally in the ratio of payoffs to handling costs, then all cars are part of the 'diet' and should be taken immediately upon encounter. Cars encountered more frequently will appear in the diet more often and, in fact, will be stolen at a frequency proportional to $\lambda_{i}$. One should therefore expect a strong correlation between relative abundances and theft rates if the null hypothesis is true. Failure to reject the null hypothesis implies that car thieves are unspecialized foragers and take only what is presented to them by the environment. Rejection of the null hypothesis, for all or even some car types, may constitute evidence that differential payoffs and/or handling costs enter into car thieves' situational foraging decisions. Under these circumstances we can evaluate the role that payoffs and/or handling costs may play in driving target choice.

\section{Methods}

Car types are defined as unique make-models or, where necessary, make-model-years. For example, 1992 and 2002 Honda Civics may be different car types, from the point of view of the offender, because they have different perceived payoffs and may also differ in how easy they are to break into and 'hot wire' (Farrell et al. 2011). An initial database of car make-model-years was assembled using a popular car shopping and research website, www.edmonds.com. A student assistant was then trained to quickly and accurately identify car types in pilot surveys of a university campus parking structures.

Street-based surveys were conducted in three Los Angeles zip codes (90034, 90045 and 90291) during two excursions in October-December 2004 and OctoberDecember 2005. The three survey locations had the highest volume of car thefts in 2003 among zip codes on the Los Angeles West Side. Surveys involved walking between one and three contiguous blocks, first up one side and then down the other. Surveys on the exact same block segments were conducted at two-hour intervals between 6AM and 6PM. The most dramatic change in density of cars parked on the street occurred between $6 \mathrm{AM}$ and 8AM. I therefore assume that the mix of car types seen at 6AM represents the overnight diversity. Only vehicles in publically accessible street locations were recorded. The observed relative frequency of each car type $i$ is used as a measure of encounter rate $\lambda_{i}$.

Expected value on the illegal market is used as a proxy for the payoffs $e_{i}$ associated with stealing different car types (Copes 2003; Matsueda et al. 1992). I do not assume that all car thieves seek cash. Rather, illegal market value is a generic currency that is expected to be positively correlated with non-monetary payoffs. For example, a 'hot car' is not only more likely to demand more money in an illegal market context, but it is also expected to have a higher payoff in excitement and prestige for the teenage car thief. Illegal market value is calculated as $e_{i}=f \sum_{i} p_{i} v_{i}$, where $p_{i}$ is the proportion of cars of a given make-model-year stolen, $v_{i}$ is the legal market value of the car at the time of theft as determined from the Kelley Blue Book (DeBacker 2003), and $f$ is the fraction of the legal market value realized on the illegal market. I assume that $f=0.1$, but choice of a different constant does not impact the results.

I use break-in times as a proxy for overall handling costs $h_{i}$. The UK-based "What Car?" Security Supertest (Secured by Design 2000, 2003) conducted attack testing of new cars marketed in the UK. The tests evaluated the ability of new vehicles to withstand attacks by trained locksmiths using the non-destructive entry techniques commonly deployed by car thieves. The tests included 123 unique make-models and measured the time, in seconds, needed to gain entry to each vehicle. A car was considered to pass the test if it was not possible to gain entry within two minutes. Break-in time represents only one of the handling costs associated with car theft. I assume, however, that the handling costs at different critical points in the theft process are positively correlated. For example, if a car is easy to enter, it is also more likely to be easy to 'hot wire', less likely to have a geo-location device installed and be easier to chop.

Evaluation of the relationships between car theft, environmental abundances, payoffs and handling costs is conducted using non-parametric statistics that are robust to ordinal scale data and non-normal distribution characteristics (Conover 1998). Theft frequencies and environmental abundances are compared using Kendall's $\tau$, a generalized correlation coefficient that measures the similarity of ranked order lists. Kendall's $\mathrm{\tau} b$ allows for rank order ties. Illegal market values and break-in times among common and rare cares are non-normally distributed. Medians therefore provide the most robust measure of central tendency and the non-parametric Mann-Whitney U the most appropriate corresponding statistical test. Differences in distribution shape are computed using the non-parametric Kolmogorov-Smirnov D. 


\section{Results}

Between 1 Jan 2003 and 31 December 2004, 63,528 vehicles were reported stolen within the City of Los Angeles (Federal Bureau of Investigation 2003-2006). In zip codes 90034, 90045 and 90291, located on the West Side of Los Angeles and representing $\sim 3.5 \%$ of the land area of the City, a total of 2,251 cars were stolen during the same period, or $\sim 3.5 \%$ of all thefts. These cars are divided into 271 unique make-model types. The Honda Civic and Accord, Toyota Camry and Corolla, and Nissan Sentra together comprise $\sim 25 \%$ of the total thefts and 87 car types are represented by single thefts (Figure 1A, Table 1).

To test whether the observed bias in thefts towards some car types is driven by environmental abundance, I conducted surveys of main artery and residential streets (see Methods). A total of 1,825 cars were observed and these were classified into 262 unique make-model types. As with reported thefts, the cars available on the streets are dominated by a few types (Figure 1B). Seventy seven types identified in the survey are singletons. The distribution is qualitatively similar to rank species abundance curves in ecology, which show environments numerically dominated by a few species, but most of the richness is accumulated through species with small numbers of individuals Hubbell (2001). Here I focus on the top 25 most commonly stolen cars. These car types account for $53 \%$ of the total observed volume of stolen cars $(N=1198)$ and the bulk of the variation in theft frequency.

A comparison of theft and density rank order frequencies shows a significant positive relationship (Kendall's T $\mathrm{b}=0.491, \mathrm{p}<0.001$ ) (Figure 2). Thirteen of the top 25 most stolen cars are also in the top 25 for abundance (Table 1). In general, the most common cars on the street are also the most stolen. The positive relationship between abundance and theft is particularly strong among the top nine most stolen cars (Kendall's $\mathrm{\tau} \quad \mathrm{b}=$ 0.611, $\mathrm{p}=0.022$ ). Honda Civics are the most abundant cars and the most frequently stolen. For the top nine cars it is difficult to reject the null hypothesis that environmental abundance is driving the targeting of these vehicles for theft.

Note, however, that approximately one half $(N=12)$ of the top 25 most stolen cars are not in the top 25 for abundance. Several of these are significant outliers (Table 1). For example, the Chrysler $300 \mathrm{M}$ is ranked 14 , with 33 thefts in 2003-04, but was observed only
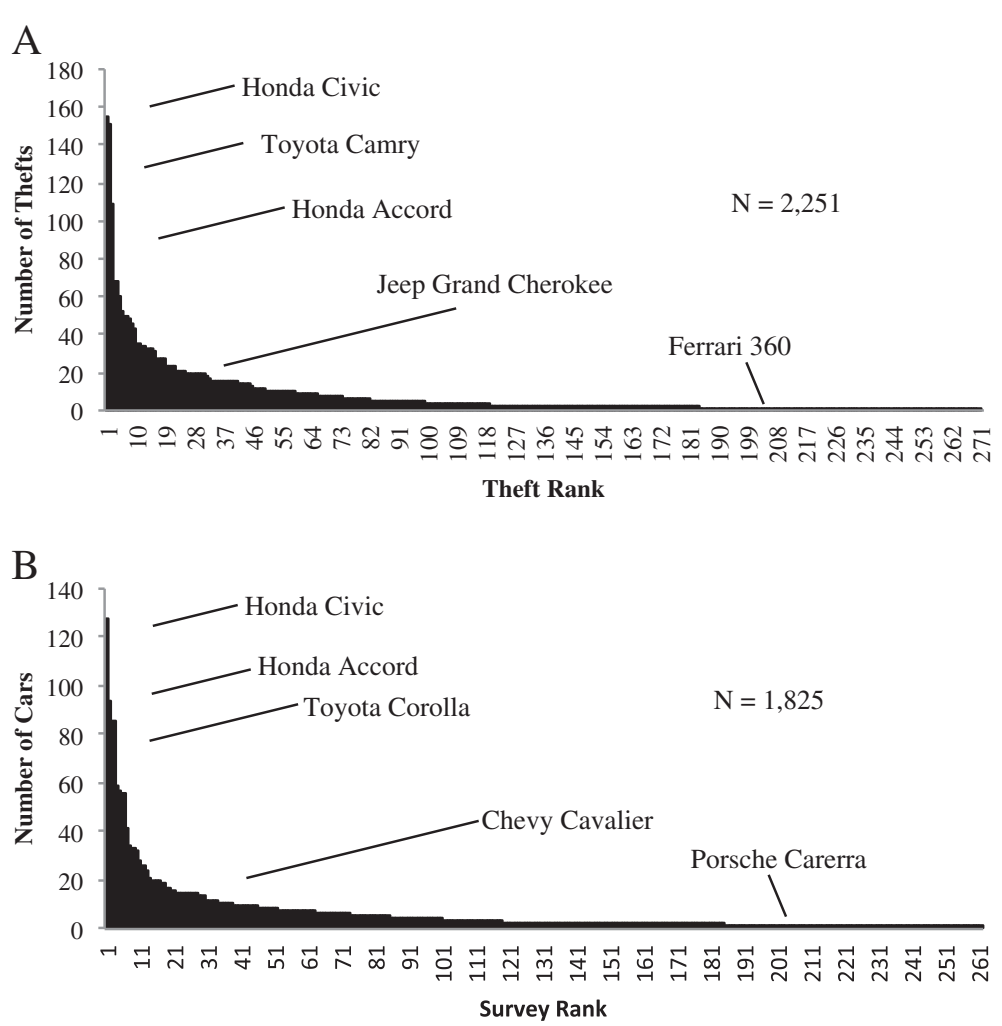

Figure 1 Rank order plots of make-model car types stolen and observed in street-based surveys in three Los Angeles zip codes.

(A) Cars stolen in zip codes 90034, 90045 and 90291 between Jan 1, 2003 and December 31, 2004 are numerically dominated by a few car types. (B) The rank order abundance of car types in the same zip codes, observed in street surveys conducted in 2004 and 2005, reveals the structure of car theft opportunities. 
Table 1 The top 25 most stolen car types in 2003-2004 and their environmental densities in Los Angeles zip codes 90034, 90045 and 90291

\begin{tabular}{|c|c|c|c|c|c|c|c|c|}
\hline Make-model & Theft $\mathbf{N}$ & Survey $\mathrm{N}$ & Recovery N & Theft $p$ & Survey $p$ & Recovery $p$ & Theft rank & Survey rank \\
\hline HONDA CIVIC & 155 & 128 & 110 & 0.069 & 0.070 & 0.710 & 1 & 1 \\
\hline TOYOTA CAMRY & 151 & 59 & 118 & 0.067 & 0.032 & 0.781 & 2 & 4 \\
\hline HONDA ACCORD & 109 & 94 & 81 & 0.048 & 0.052 & 0.743 & 3 & 2 \\
\hline TOYOTA COROLLA & 68 & 86 & 47 & 0.030 & 0.047 & 0.691 & 4 & 3 \\
\hline NISSAN SENTRA & 60 & 33 & 45 & 0.027 & 0.018 & 0.750 & 5 & 9 \\
\hline ACURA INTEGRA & 52 & 21 & 28 & 0.023 & 0.012 & 0.538 & 6 & 14 \\
\hline FORD MUSTANG & 50 & 20 & 41 & 0.022 & 0.011 & 0.820 & 7 & 16 \\
\hline FORD EXPLORER & 49 & 57 & 35 & 0.022 & 0.031 & 0.714 & 8 & 5 \\
\hline FORD TAURUS & 46 & 28 & 36 & 0.020 & 0.015 & 0.783 & 9 & 11 \\
\hline PONTIAC GRAND AM/PRIX & 43 & 4 & 38 & 0.019 & 0.002 & 0.884 & 10 & 110.5 \\
\hline NISSAN ALTIMA & 35 & 42 & 27 & 0.016 & 0.023 & 0.771 & 11 & 7 \\
\hline CHEVY IMPALA & 34 & 6 & 26 & 0.015 & 0.003 & 0.765 & 12.5 & 79.5 \\
\hline DODGE STRATUS & 34 & 5 & 30 & 0.015 & 0.003 & 0.882 & 12.5 & 93.5 \\
\hline CHRYSLER 300M & 33 & 1 & 31 & 0.015 & 0.001 & 0.939 & 14 & 224 \\
\hline CHEVY BLAZER & 32 & 15 & 24 & 0.014 & 0.008 & 0.750 & 15 & 25 \\
\hline CHRYSLER PT CRUISER & 31 & 8 & 26 & 0.014 & 0.004 & 0.839 & 16 & 58 \\
\hline DODGE CARAVAN & 28 & 8 & 18 & 0.012 & 0.004 & 0.643 & 17.5 & 58 \\
\hline DODGE INTREPID & 28 & 9 & 23 & 0.012 & 0.005 & 0.821 & 17.5 & 49.5 \\
\hline JEEP CHEROKEE & 27 & 34 & 16 & 0.012 & 0.019 & 0.593 & 19 & 8 \\
\hline LINCOLN TOWN CAR & 24 & 4 & 22 & 0.011 & 0.002 & 0.917 & 20 & 110.5 \\
\hline DODGE NEON & 23 & 2 & 19 & 0.010 & 0.001 & 0.826 & 21.5 & 165.5 \\
\hline FORD FOCUS & 23 & 7 & 20 & 0.010 & 0.004 & 0.870 & 21.5 & 68.5 \\
\hline CHRYSLER SEBRING & 21 & 3 & 15 & 0.009 & 0.002 & 0.714 & 24 & 132.5 \\
\hline FORD EXPEDITION & 21 & 12 & 13 & 0.009 & 0.007 & 0.619 & 24 & 32.5 \\
\hline JEEP GRAND CHEROKEE & 21 & 20 & 14 & 0.009 & 0.011 & 0.667 & 24 & 16 \\
\hline
\end{tabular}

Note: Theft and recovery proportions are calculated with respect to all 2,251 cars stolen. Survey proportions are calculated with respect to the 1,825 unique car types identified in street-based surveys.

Environmental densities were measured in two survey periods October-December 2004 and October-December 2005.

once in the 1,825 cars identified in street surveys (survey rank $=224$ ). Similarly, the Pontiac Grand AM was ranked 10, with 44 thefts, but was observed only four times in the same surveys (survey rank $=110.5$ ). It may be that thieves targeted these rare cars based on specialized evaluation of the expected payoffs, handling costs, or both, made at the time of encounter.

Taking into account car make, model and year, I calculated the expected illegal market value for each car stolen in 2003 as $10 \%$ of the Kelley Blue Book value at the time of theft (see Methods) (DeBacker 2003; Stevenson and Forsythe 1998; Tremblay et al. 2001). Illegal market value is used as broad proxy for both monetary and non-monetary payoffs. Figure 3 shows that the distribution of expected illegal market values for the outliers is significantly different from that associated with environmentally common cars (Mann-Whitney $\mathrm{U}=$ 8562, Wilcoxon $=73542, \mathrm{Z}=-11.327, \mathrm{p}<.001)$.
Among the environmentally common cars, the median expected illegal market value is $\$ 740$ ( $\min =\$ 293$, $\max =$ $\$ 2,916)$. Among the environmentally rare cars, the median is twice as large at $\$ 1,515(\min =\$ 210, \max \$ 4,493)$. These data suggest that the outliers within the sample of stolen cars may be targeted because they offer a higher expected payoff.

It is also possible that ease-of-theft is responsible for the observed outliers (Farrell et al. 2011; Light et al. 1993; Wiles and Costello 2000). The UK-based "WhatCar?" Security Supertest (Secured by Design $2000,2003)$, evaluated the ability of a range of new vehicles to withstand attacks using non-destructive entry techniques (see Methods). Break-in time is used as a proxy for handling costs at all stages of the theft process. The aggregated results from 2000 and 2003, excluding those cars that passed the test, show a weak, but significant relationship between break-in times and 


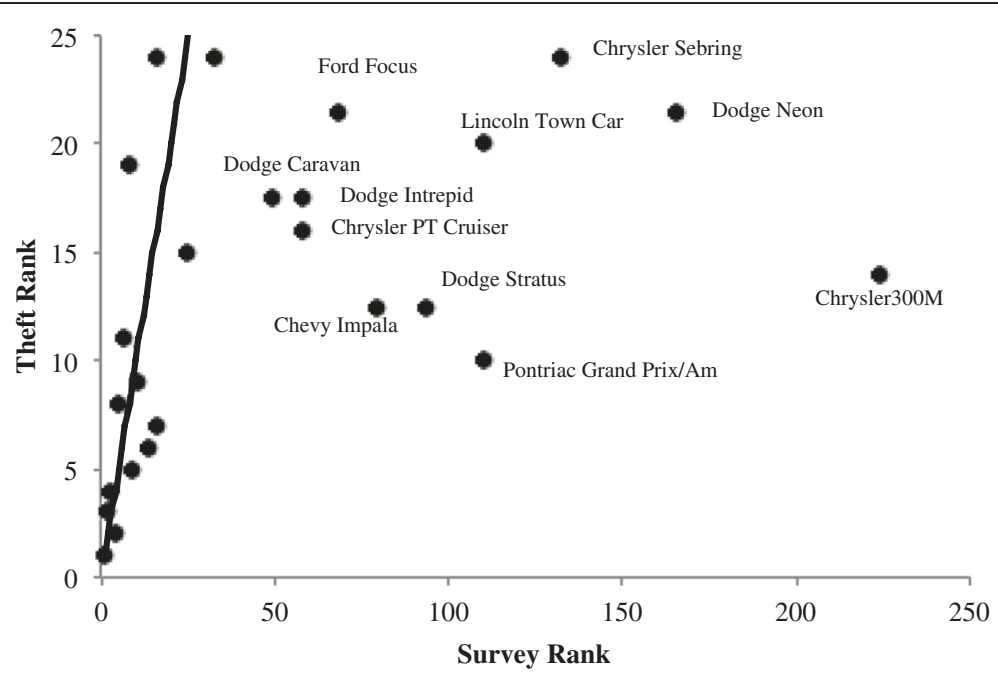

Figure 2 A scatter plot of abundance rank order against theft rank order shows a strong positive relationship between car availability and theft risk. Eleven car-types are stolen much more frequently than their environmental abundance would suggest. Line represents a hypothetical 1:1 relationship between rank abundance and rank theft.

market price in US Dollars $\left(r^{2}=.258, \mathrm{p}<.001\right)$ (Figure 4A). The median break-in time for all vehicle types successfully attacked was 29 seconds and the minimum time was two seconds. Twenty three cars $(\sim 19 \%)$ have break-in times under 15 seconds.
Vehicle make-models are not equivalent between the UK and US markets, despite similar names, and comparable data are not available from US contexts. It is not possible therefore to map break-in times from the Security Supertests directly to car types stolen in the US

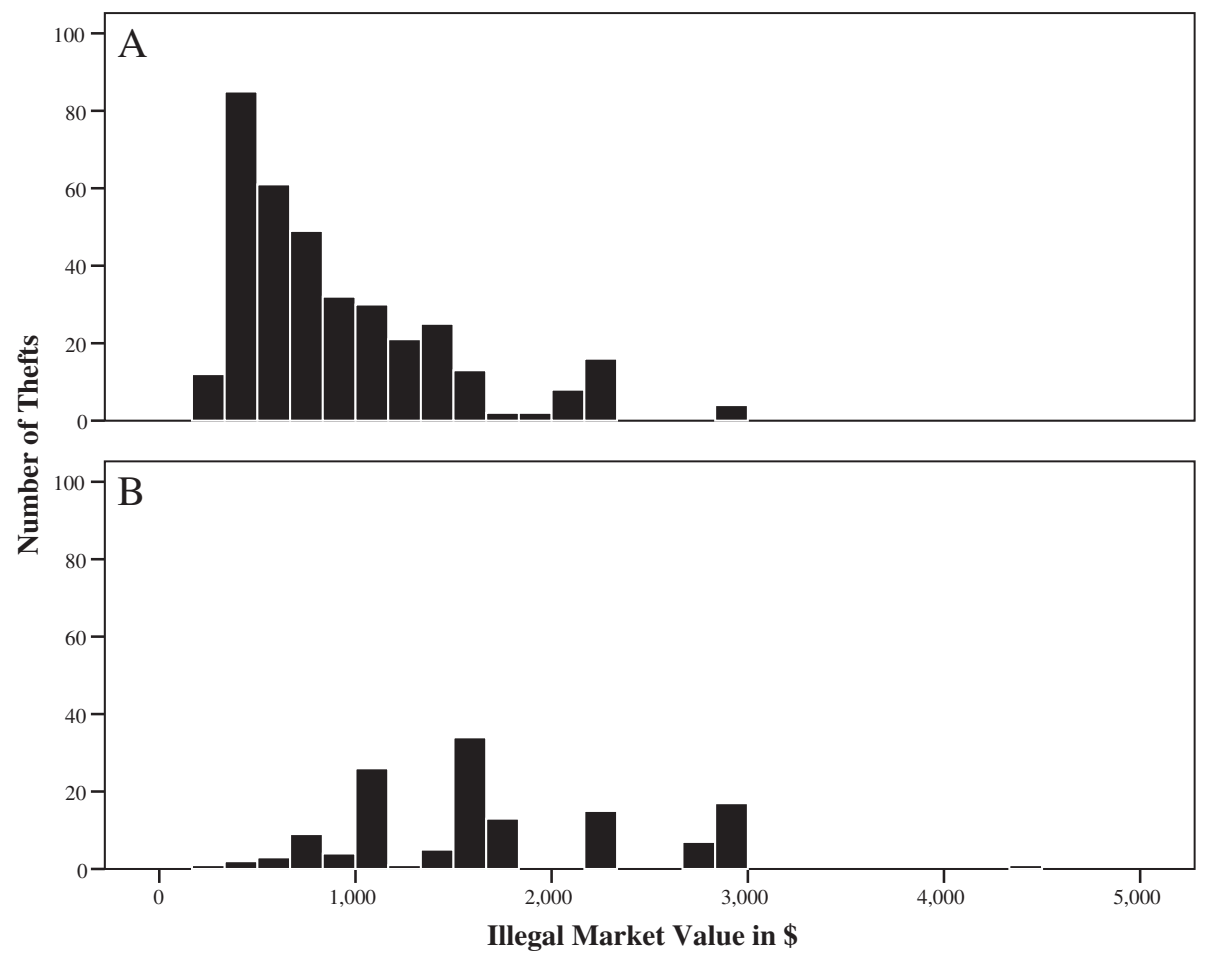

Figure 3 Frequency histograms of the estimated illegal market values show much lower expected payoffs may be attributed to the top nine most stolen cars $(A)$, where density is expected to the major determinant of theft, compared with the outliers (B), where environmental density is not implicated. 


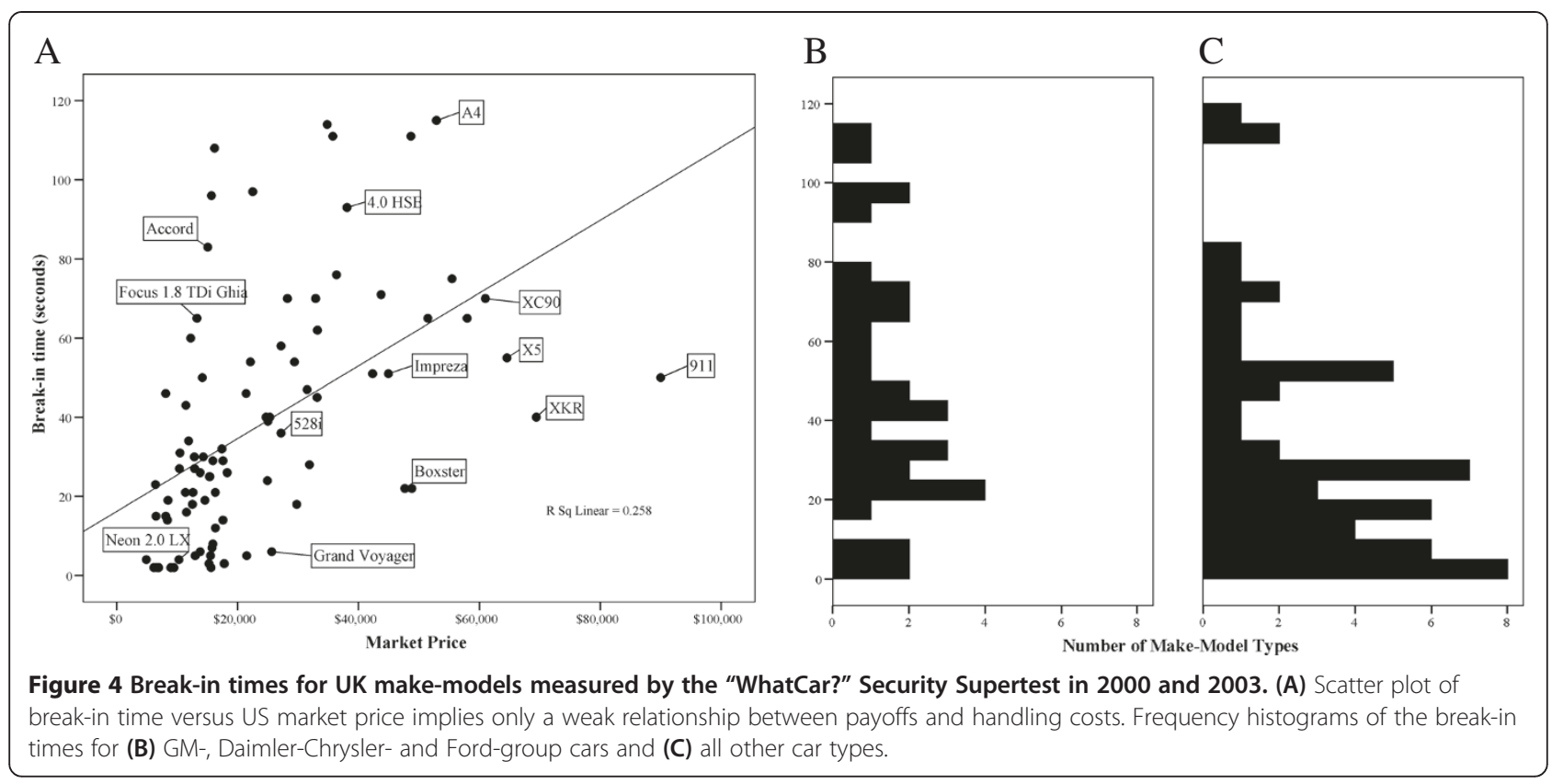

using the UK data. However, some indication of handling costs may be gained by examining patterns within manufactures. Seven of the cars stolen in disproportion to their environmental density were manufactured by Daimler-Chrysler, three by Ford and two by GM (Table 1). Of the 123 cars tested in the Security Supertests, 44 were vehicles by these manufacturers. Eleven (25\%) successfully withstood attacks lasting two minutes, compared with 24 of the remaining 79 car types (44\%). The data may suggest that Daimler-Chrysler, GM and Ford vehicles are more broadly susceptible to attack. However, a range of break-in times characterize the vehicles that did not pass the test (Table 2). Low and high-mid market cars sold under the Chrysler brand (e.g., Neon, Grand Voyager) have minimum break-in times of between four and six seconds, while one low-market GM car sold under the Vauxhall brand had a brake-in time of two seconds. Midmarket GM cars, also sold under the Vauxhall brand, had a mean break-in time of 81 seconds. The aggregate results do not indicate that cars made by DaimlerChrysler, Ford or GM are disproportionately easier for car thieves to handle. Indeed, cars marketed by other manufacturers show a significant skew towards shorter break-in times and, by implication, lower handling costs for thieves (Kolmogorov-Smirnov $\mathrm{Z}=1.349$, $p=0.053$ ) (Figure 4B,C).

\section{Discussion and conclusion}

It is difficult to reject the null hypothesis that environmental abundance is the primary determinant of what cars are targeted for theft. There is a particularly strong relationship between abundance and theft rank for the top-nine most stolen cars. In the CRAVED conceptual framework put forward by Clarke (1999), availability would seem to outweigh other dimensions that might influence theft choice. In the instances where cars are targeted despite being rare, payoff differences may play some role. Car recovery rates provide one measure of the importance of non-monetary, or possibly limited monetary payoffs to car theft (Clarke and Harris 1992). There is little systematic difference in the rate of recovery across car types (Table 1), suggesting that none of the top 25 most stolen cars are disproportionately landing in fully-body chop shops or being stolen for export. The payoffs here seem to be primarily non-monetary. Furthermore, among the outliers that are stolen despite being rare, it appears that the newest model years are targeted. For example, eight of 12 Chrysler 300s and seven of 13 Chrysler Sebrings stolen during 2003 were 2004 model years, which became available only in the last five months of the year. The implication is that these cars, though rare, were targeted precisely because they were perceived to be 'hot rides' (Wiles and Costello 2000). That some cars are more valuable or enjoyable can override their low availability, but this occurs infrequently.

It is less apparent that lower handling costs biased thieves' decisions to target environmentally rare cars, although ethnographic work suggests that handling costs are often a significant concern (Clarke 1999; Light et al. 1993; Wiles and Costello 2000). Recent research suggests that the potential for encountering opposition from car owners is a major concern (Copes and Tewksbury 2011), but it is uncertain how the probability of opposition might relate to car type. Direct handling costs may have played a role in driving Los Angeles car thieves to 
Table 2 Break-in times in seconds for Daimler-Chrysler, Ford and GM brands sold in the UK tested in the "WhatCar?" Security Supertest in 2000 and 2003

\begin{tabular}{|c|c|c|c|c|c|c|c|}
\hline Manufacturer & Make-model & Market & $\mathbf{N}$ & $\begin{array}{c}\text { Mean } \\
\text { (seconds) }\end{array}$ & $\begin{array}{c}\sigma \\
\text { (seconds) }\end{array}$ & $\begin{array}{c}\text { Min } \\
\text { (seconds) }\end{array}$ & $\begin{array}{c}\text { Max } \\
\text { (seconds) }\end{array}$ \\
\hline Daimler-Chysler & Chrysler Neon & Low & 1 & & & 4 & \\
\hline Daimler-Chysler & Mercedes A Class & Mid & 1 & & & 30 & \\
\hline Daimler-Chysler & Chrysler Grand Voyager & High-mid & 1 & & & 6 & \\
\hline Daimler-Chysler & Mercedes C, E Class & High & 2 & 70 & 7.07 & 65 & 75 \\
\hline Ford & $\begin{array}{l}\text { Fiesta, Focus Ghia Estate, Ka 3, } \\
\text { Mazda } 626 \text { Sport }\end{array}$ & Low & 4 & 40.75 & 15.9 & 23 & 60 \\
\hline Ford & $\begin{array}{l}\text { Focus TDi Ghia, Ka, Streetka, Landrover } \\
\text { Freelander, Mazda MPV, Mazda Premacy }\end{array}$ & Mid & 6 & 33.83 & 17.08 & 19 & 65 \\
\hline Ford & Focus, Land Rover Discovery, Mazda 6 & High-mid & 3 & 43 & 13.45 & 28 & 54 \\
\hline Ford & $\begin{array}{l}\text { Mondeo, Jaguar XKR, Range Rover } 4.0 \\
\text { HSE, Volvo XC90 }\end{array}$ & High & 4 & 69 & 21.76 & 40 & 93 \\
\hline GM & Vauxall Agilla, Astra & Low & 2 & 12 & 13.44 & 2 & 21 \\
\hline GM & Vauxall Corsa, Frontera, Meriva, Zafira & Mid & 4 & 81 & 40.04 & 21 & 108 \\
\hline GM & Saab 93, Saab 95, Vauxall Astra & High-mid & 3 & 45.67 & 10.69 & 39 & 58 \\
\hline GM & Cadillac Seville STS, Vauxall Vectra & High & 2 & 58 & 74.95 & 5 & 111 \\
\hline $\begin{array}{l}\text { Total Daimler-Chrysler, } \\
\text { GM, Ford }\end{array}$ & & & 33 & 46.88 & 30.68 & 2 & 111 \\
\hline Other Car types & & & 55 & 32.22 & 29.36 & 2 & 115 \\
\hline
\end{tabular}

ignore certain environmentally common cars. Seven make-model types including the Volkswagen Jetta, Toyota RAV4 and Nissan Xterra ranked within the top 25 for abundance, but were rarely or never stolen (Table 3 ). An average of $57 \%$ of the vehicles sold by the corresponding manufactures in the UK passed the Security Supertests. This is compared only 25\% of Daimler-Chrysler, GM and Ford cars representative of the environmentally rare group. The implication is that these cars may be ignored because they are more resistant to attack. Detailed attack analyses of cars from the US market could help resolve the exact role of handling costs in the differential targeting of some cars.
In spite of the narrow role that differential payoffs and handling costs appear to play the choice of which cars to steal, one must be careful to not fall prey to the ecological fallacy. Ethnographic evidence points to a degree of specialization among car thieves, with distinctions among those engaged in opportunistic theft and those in organized crime, and among younger and older offenders. Such specializations are not directly visible in aggregate car theft data. It is possible that the population of Los Angeles car thieves consists of several different types each with their preferred prey. The observed frequency of stolen car types might therefore represent a mixture of fixed, independent strategies, some rare and

Table 3 Environmentally abundant cars of low theft rank in zip codes 90034, 90045 and 90291 and the aggregated 2000 and 2003 "WhatCar?" Security Supertest results for cars from the corresponding manufacturers

\begin{tabular}{|c|c|c|c|c|c|c|c|c|c|c|c|}
\hline Make-model & Theft $\mathbf{N}$ & Survey N & $\begin{array}{l}\text { Theft } \\
\text { rank }\end{array}$ & $\begin{array}{l}\text { Survey } \\
\text { rank }\end{array}$ & $\mathrm{N}$ tested & Passing $p$ & Models failing & Mean (s) & $\sigma(s)$ & Min (s) & $\operatorname{Max}(\mathrm{s})$ \\
\hline Volkswagen Jetta & 9 & 56 & 63 & 6 & 6 & 0.50 & $\begin{array}{l}\text { Lupo 1.4S, Polo Gti, } \\
\text { Golf 1.6SE }\end{array}$ & 32 & 16.09 & 19 & 50 \\
\hline Toyota RAV4 & 5 & 19 & 91 & 18 & 8 & 0.63 & $\begin{array}{c}\text { Yaris Verso, Corolla, } \\
\text { Avensis }\end{array}$ & 46.33 & 15.50 & 31 & 46 \\
\hline Lexus ES & & 15 & 229 & 25 & 3 & 0.67 & IS & & & 111 & \\
\hline Nissan Xterra & 2 & 16 & 164 & 21 & 5 & 0.80 & Micra 1.3 SE & & & 14 & \\
\hline Volvo S Class & & 17 & 229 & 19.5 & 3 & 0.67 & XC90 & & & 70 & \\
\hline Subaru Outback & 2 & 15 & 164 & 25 & 3 & 0.00 & $\begin{array}{l}\text { Impreza, Impreza } \\
\text { Turbo, Legacy }\end{array}$ & 22.67 & 24.79 & 5 & 51 \\
\hline
\end{tabular}


some common, not variation in the behavior of offenders in general. The converse is also potentially true. There is a danger of falling prey to an ethnographic fallacy that confounds our ability to infer aggregate characteristics from ethnographically rich data collected at an individual scale. To wit, given interviews with tens of car thieves about their offending preferences, can we reliably infer the population characteristics of the many thousands of individuals likely responsible for the 63,000 cars stolen in Los Angeles in 2003-2004? There is no easy way to resolve the ecological or ethnographic fallacy. I suspect, however, that the unspecialized foragers responding primarily to environmental abundances greatly outnumber the specialists, making the latter practically invisible in aggregate data.

The results described here are important for understanding the broader causes of criminal behavior and may suggest novel approaches to crime prevention based on formal ecological models (see also Bernasco 2009; Brantingham et al. 2012; Felson 2006). The unspecialized nature of car theft in Los Angeles implies that the behavioral and cognitive capacities needed to be a successful thief are generic. Indeed, humans are well-equipped to become effective foragers for criminal opportunities given an evolved psychology to solve foraging problems in boundedly-rational ways (Hutchinson et al. 2007), combined with small amounts of individual trial-and-error or social learning (Akers 2008; Boyd and Richerson 1985). Indeed, the co-offending that characterizes the early careers $(<20$ years old $)$ of most offenders, including car thieves, is ideally suited to the transmission of the simple skills sufficient to produce experts from inexperienced thieves (Reiss and Farrington 1991). That auto theft in Los Angeles is driven primarily by environmental structure provides further evidence that the greatest gains in crime prevention are to be had in altering the structure of criminal opportunity (Brantingham and Brantingham 1981; Farrell et al. 2011; Felson and Clarke 1998). How environmental alterations impact situational foraging behaviors and longer-term population trajectories are well-studied within ecology (Henle et al. 2004; Kerr et al. 2007), suggesting a way forward for formal crime ecology.

\section{Competing interests}

The author declares that he has no competing interests.

\footnotetext{
Acknowledgements

This work was supported in part by grants NSF-FRG DMS-0968309, ONR N000141010221, ARO-MURI W911NF-11-1-0332, and AFOSR-MURI FA9550-10-1-0569, and by the UCLA Faculty Senate. I am indebted to the Los Angeles Police Department for providing the data analyzed here. Thank you to David Bell from Secured by Design and Silas Borden for assistance with the street-based surveys.
}

Received: 29 November 2012 Accepted: 29 April 2013 Published: 3 July 2013

\section{References}

Akers, R (2008). Social learning and social structure: A general theory of crime and deviance. Boston: Northeastern University Press.

Bernasco, W. (2009). Foraging strategies of homo criminalis: lessons from behavioral ecology. Crime Patterns and Analysis, 2(1), 5-16.

Boyd, R, \& Richerson, PJ (1985). Culture and the Evolutionary Process. Chicago: University of Chicago Press.

Brantingham, PJ, \& Brantingham, PL (1981). Environmental Criminology. Beverly Hills: Sage.

Brantingham, PJ, Tita, GE, Short, MB, \& Reid, SE. (2012). The ecology of gang territorial boundaries. Criminology, 50(3), 851-885.

Charnov, EL. (1976). Optimal foraging - attack strategy of a mantid. American Naturalist, 110(971), 141-151.

Clarke, RV. (1999). Hot Products: Understanding, Anticipating and Reducing Demand for Stolen Goods (Police Research Series, Paper 112.). London: Home Office.

Clarke, RV, \& Harris, PM (1992). Auto Theft and its Prevention. In M Tonry (Ed.), Crime and Justice: A Review of Research (Vol. 16, pp. 1-54). Chicago: University of Chicago Press.

Conover, WJ. (1998). Practical Nonparametric Statistics. Hoboken: Wiley.

Copes, H. (2003). Streetlife and the rewards of auto theft. Deviant Behavior 24(4), 309-332.

Copes, H, \& Cherbonneau, M. (2006). The key to auto theft - Emerging methods of auto theft from the offenders' perspective. British Journal of Criminology, 46(5), 917-934

Copes, H, \& Tewksbury, R. (2011). Criminal experience and perceptions of risk: what auto thieves fear when stealing cars. Journal of Crime and Justice, $34(1), 62-79$.

Cornish, DB, \& Clarke, RV (1986). Introduction. In DB Cornish \& RV Clarke (Eds.), The Reasoning Criminal: Rational Choice Perspectives on Criminal Offending. New York: Springer-Verlag.

Cornish, DB, \& Clarke, RV. (1987). Understanding crime displacement: An application of rational choice theory. Criminology, 25(4), 933-947.

DeBacker, P (Ed.). (2003). Kelley Blue Book Used Car Guide Consumer Edition 1988-2002. Irvine, CA: Kelly Blue Book.

Dhami, MK. (2008). Youth auto theft: a survey of a general population of canadian youth. Canadian Journal of Criminology and Criminal Justice, 50(2), 187-209.

Farrell, G, Tseloni, A, \& Tilley, N. (2011). The effectiveness of vehicle security devices and their role in the crime drop. Criminology and Criminal Justice, 11(1), 21-35

Federal Bureau of Investigation (2003-2006). Crime in the United States, Uniform Crime Reports. http://www.fbi.gov/ucr/ucr.htm.

Felson, M (2006). Crime and Nature. Thousand Oaks: Sage.

Felson, M, \& Clarke, RV (1998). Opportunity Makes the Thief: Practical Theory for Crime Prevention (Police Research Series Paper 98). London: Home Office Policing and Reducing Crime Unit.

Freeman, RB. (1996). Why do so many young american men commit crimes and what might we do about it? The Journal of Economic Perspectives, 10(1), 25-42.

Freeman, RB. (1999). The economics of crime. Handbook of Labor Economics, 3, 3529-3571

Gottfredson, MR, \& Hirschi, T (1990). A General Theory of Crime. Stanford: Stanford University Press.

Hames, RB, \& Vickers, WT. (1982). Optimal diet breadth theory as a model to explain variability in Amazonian hunting. American Ethnologist, 9(2), 358-378.

Henle, K, Davies, KF, Kleyer, M, Margules, C, \& Settele, J. (2004). Predictors of species sensitivity to fragmentation. Biodiversity and Conservation 13(1), 207-251

Hubbell, SP (2001). The Unified Neutral Theory of Biodiversity and Biogeography. Princeton: Princeton University Press.

Hughes, RN, \& Dunkin, SD. (1984). Behavioral components of prey selection by Dogwhelks, Nucella-Lapillus (L), feeding on Mussels, Mytilus-Edulis-L, in the Laboratory. Journal of Experimental Marine Biology and Ecology, 77(1-2), 45-68.

Hutchinson, JMC, Wilke, A, \& Todd, PM. (2007). Patch leaving in humans: can a generalist adapt its rules to dispersal of items across patches? Animal Behavior, 75, 1331-1349.

Jacobs, BA, Topalli, V, \& Wright, R. (2003). Carjacking, streetlife and offender motivation. British Journal of Criminology, 43(4), 673-688.

Johnson, SD, Summers, L, \& Pease, K. (2009). Offender as forager? a direct test of the boost account of victimization. Journal of Quantitative Criminology, 25(2), $181-200$ 
Kellett, S, \& Gross, H. (2006). Addicted to joyriding? An exploration of young offenders' accounts of their car crime. Psychology Crime \& Law, 12(1), 39-59.

Kerr, JT, Kharouba, HM, \& Currie, DJ. (2007). The macroecological contribution to global change solutions. Science, 316(5831), 1581-1584.

Krebs, JR, Erichsen, JT, Webber, MI, \& Charnov, EL. (1977). Optimal prey selection in great tit (parus-major). Animal Behaviour, 25(FEB), 30-38.

Langworthy, RH, \& Lebeau, JL. (1992). The spatial-distribution of sting targets. Journal of Criminal Justice, 20(6), 541-551.

Lantsman, L. (2013). "Moveable currency": the role of seaports in export oriented vehicle theft. Crime, Law and Social Change, 59(2), 157-184.

Light, R, Nee, C, \& Ingham, H (1993). Car Theft: The Offender's Perspective (Home Office Rresearch Study No. 30). London: Home Office.

Lu, YM. (2003). Getting away with the stolen vehicle: an investigation of journeyafter-crime. The Professional Geographer, 55(4), 422-433.

Matsueda, RL, Piliavin, I, Gartner, R, \& Polakowski, M. (1992). The prestige of criminal and conventional occupations: a subcultural model of criminal activity. American Sociological Review, 57(6), 752-770.

Nagin, DS, \& Paternoster, R. (1994). Personal capital and social control: the detterence implications of a theory of individual differences in criminal offending. Criminology, 32(4), 581-606.

Prugh, LR. (2005). Coyote prey selection and community stability during a decline in food supply. Oikos, 110(2), 253-264.

Pyke, GH. (1984). Optimal foraging theory - a critical-review. Annual Review of Ecology and Systematics, 15, 523-575.

Reiss, AJ, \& Farrington, DP. (1991). Advancing knowledge about co-offending: results from a prospective longitudinal survey of London males. The Journal of Criminal Law and Criminology, 82(2), 360-395.

Secured by Design (2000, 2003). The "WhatCar?" Security Supertests were conducted in 2000 and 2003. The attack tests are described online at http://www.whatcar.co.uk/news-special-report.aspx?NA $=204498$.

Smith, EA (1991). Inujjuamiut Foraging Strategies: Evolutionary Ecology of an Arctic Hunting Economy. New York: Aldine de Gruyter.

Stephens, DW, \& Krebs, JR (1986). Foraging Theory. In. Princeton: Princeton University Press.

Stevenson, RJ, \& Forsythe, LMV (1998). The Stolen Goods Market in New South Wales. Sydney: New South Wales Bureau of Crime Statistics and Research.

Suresh, G, \& Tewksbury, R. (2999). Locations of motor vehicle theft and recovery. American Journal of Criminal Justice, 1-16.

Tremblay, P, \& Morselli, C. (2000). Patterns in criminal achievement: Wilson and Abrahamse revisited. Criminology, 38(2), 633-659.

Tremblay, P, Talon, B, \& Hurley, D. (2001). Body switching and related adaptations in the resale of stolen vehicles. Script elaborations and aggregate crime learning curves. British Journal of Criminology, 41(4), 561-579.

Wiles, P, \& Costello, A (2000). The 'Road to Nowhere': The Evidence for Travelling Criminals (Report 207). London: Home Office.

Wilson, JQ, \& Abrahamse, A. (1992). Does crime pay? Justice Quarterly, 9, 359-377.

Wright, R, Brookman, F, \& Bennett, T. (2006). The foreground dynamics of street robbery in Britain. British Journal of Criminology, 46(1), 1-15.

Wright, RT, \& Decker, SH (1994). Burglars on the Job: Streetlife and Residential Breakins. Boston: Northeastern University Press.

doi:10.1186/2193-7680-2-3

Cite this article as: Brantingham: Prey selection among Los Angeles car thieves. Crime Science 2013 2:3.

\section{Submit your manuscript to a SpringerOpen ${ }^{\odot}$ journal and benefit from:}

- Convenient online submission

- Rigorous peer review

- Immediate publication on acceptance

- Open access: articles freely available online

- High visibility within the field

- Retaining the copyright to your article

Submit your next manuscript at $\gg$ springeropen.com 